\title{
Techniques for rational use of technical equipment in sunflower oilseeds production
}

\author{
Faik Safiollin ${ }^{1}$, Genadiy Minnullin ${ }^{2}$, Salavat Suleymanov ${ }^{1, *}$, Nikolai Loginov $^{1}$, and Dieter Trautz $^{3}$ \\ ${ }^{1}$ Kazan State Agrarian University, Kazan, 420015, Republic of Tatarstan, Russia \\ ${ }^{2}$ Peasant farm enterprise Minnullin G.S., village of Urustamak, Bavlinsky district, 423930, Republic of Tatarstan, Russia \\ ${ }^{3}$ Faculty of Agricultural Sciences and Landscape Architecture, University of Applied Sciences, Osnabrück, Germany
}

\begin{abstract}
The paper summarizes the 5-year experimental data of the authors on the study of various technologies for sunflower cultivation in the soil and climatic conditions of the Republic of Tatarstan. Particular attention is paid to improving the methods of rational use of modern technological means with regards to the biological characteristics of the studied culture. It has been established that the classical technology of sunflower cultivation with deepening of the arable layer, diagonal closing of moisture, presowing cultivation to the depth of 6-8 cm, placement of rows in the South-North direction pre- and postsowing harrowing and inter-row cultivation provides $93 \%$ of the planned yield. The profitability of oilseed production is $69.2 \%$, and net profit is 13.7 thousand rubles per hectare. 7.4 thousand rubles of proceedings in cash comes to an enterprise from the sale of 1 ton of grown products. In large holding agricultural entities of Tatarstan with sunflower areas of more than 250-300 hectares, weed control using the Clearfield system excludes harrowing of crops and inter-row cultivation. The use of selective herbicide intended only for a single hybrid allows the 70 to $100 \%$ weeds destruction without damaging the main crop. The economic indicators of the mixture of the developed agricultural technology with chemical crops weeding are quite high. Specifically, the profitability is $59.6 \%$ and the cost of production of 1 ton of oilseeds is lower than its sales price by 6.7 thousand rubles.
\end{abstract}

\section{Introduction}

According to experts [1-3], 1 hectare of arable land is required for the production of 1 ton of sunflower oil, while 6 hectares of land must be allocated for the production of 1 ton of butter to contain 6 cows with a milk yield of 5 thousand liters per year, including 23 thousand dollars of capital costs and more than 300 people/hour of working time.

On the other hand, excessive consumption of animal fats is the main reason for the development of cardiovascular diseases (heart attack and stroke), which significantly reduce the life expectancy of the population of the Russian Federation. Therefore, due to changes in the diet of people over the past 10 years, the gross harvest of oilseeds in our country has a steady growth trend, which is also characteristic of the Republic of Tatarstan [4-6].

However, due to the violation of the cultivation technology, the increase in the production of oilseeds is not due to the increased yields but to the expansion of the sown area of this crop. For example, in our republic it is annually sown on an area of 100-120 thousand ha, and the yield is only $1.0-1.2 \mathrm{t} / \mathrm{ha}$ against the potential of modern varieties and hybrids being 2-3 times higher. Therefore, the development of techniques for the study object cultivation is not only relevant but also timely due to the fact that they provide at least $2.0 \mathrm{t} / \mathrm{ha}$ of oil seeds with low cost.

\section{Research conditions and methods}

Field experiments and verification of research results were carried out on the fields of peasant farm "Minnullin GS" in Bavlinsky municipal district of the Republic of Tatarstan. The agrochemical characterization of leached chernozem was typical and the humus content was $6.8 \%$ according to Tyurin, mobile phosphorus was 118 and exchange potassium was $130 \mathrm{mg} / \mathrm{kg}$ of soil according to Chirikov.

The plot area in stationary experiments was equal to the width of the studied technical means capture with sequential placement in 3 times repetition. The fertilizer application rate was determined by the calculation and balance method for the planned yield of $2.0 \mathrm{t} / \mathrm{ha}$ of sunflower oilseeds. The agrometeorological conditions during the years of research were characterized by a deficit of moisture at the beginning of the growing season and an excess during harvesting.

The research results were verified under the same conditions, on an area of 200 hectares (100 hectares of each option in a single repetition).

The studies were carried out in accordance with the methods described in the textbooks of V.F. Moi-

Corresponding author: dusai@mail.ru 
seychenko [7], V.M. Lukomets [8]. Statistical processing of the research results was carried out by analysis of variance [9].

\section{Results and its discussion}

\subsection{Primary tilling}

The world history of the last century agriculture is characterized by a continuous struggle of opinions around the primary tilling. Which is better autumn plowing, flat tilling, surface tilling at the lowest cost, or maybe direct sowing, according to the No-Till system, following the example of the USA, Canada and many European countries of the world? When it comes to fundamentally new approaches to tillage, it is necessary to take into account the biological characteristics of the cultivated crop. Thus, sunflower differs from other crops in a powerful root system, which penetrates the soil to the depth of 1.5-2.0 m, taking moisture and additional nutrients from it. In this regard, in our long-term studies, the following main tillage system turned out to be the most effective: disking + flat tilling with the arable layer deepening.

Due to the formation of a powerful deep-penetrating root system, the recommended technology eliminates massive autumn lodging of plants with large baskets compared with crops placed on surface tillage.

\subsection{Moisture closure}

Spring field work begins with moisture closure. If this work is not started on time, from 16 to 20 thousand liters of water is lost per day from each hectare of arable land. In addition, moisture closure should be accompanied by leveling the field surface, since the quality of sowing and the uniformity of emergence of seedlings depend on it. The maximum moisture retention and better leveling of the plot is achieved by the transverse-diagonal movement of the unit. For this, the field is previously divided into rectangles, the shape of which should be as close to squares as possible. A harrowing unit starts diagonally. Having reached the opposite corner adjacent to the angle of the neighboring rectangle, the tractor driver goes to this section and goes to the opposite corner. In exactly the same way, the third rectangle is harrowed. After the extreme rectangle, the machine operator makes a turn and continues moving to the joint with the track (the parallel driving navigator is the best option) made by the first move. The advantage of crossdiagonal moisture closure is good soil crumbling and leveling. With this method, the harrows do not pass twice on the same track, due to which the soil is sprayed less and its structural-aggregate composition is not disturbed. The beds remaining after autumn disking are better aligned compared to the traditional transverse moisture closure.

Most significantly, harrows with spring teeth with a working width of 24 meters should be used for highquality performance of this work. Unlike tooth harrows, which are not clogged by plant residues, are easily transported. The teeth are highly productive and not blunt.

\subsection{Pre-sowing cultivation}

Pre-sowing cultivation is carried out when calculated norms of mineral fertilizers are put to a seed placement depth of 6-8 cm, depending on the granulometric composition of the soil. To do this, it is necessary to use easily transported folding cultivators with flat legs that cut the seedlings and rosettes of weeds without wrapping wet clumps and create a compacted seedbed. In order to further align and break up the lumps, it is necessary to equip cultivators with dental harrows and plankers made of metal corners.

\subsection{Preparation of seeds for sowing}

In the soil and climatic conditions of the Republic of Tatarstan, sunflower baskets are massively affected by gray, white, dry rot and downy mildew. Therefore, presowing seed treatment with any available protectants (Apron $3 \mathrm{~kg} / \mathrm{t}$ of seeds is the best option) with addition of chelated growth stimulants containing copper 20-25 days before sowing is an obligatory agricultural technique. For these purposes, special machines PS-10 or Mobitox are used.

\subsection{Seeding-down}

Sunflower is sown with conventional beet and corn precision seeders "Multicorn" and "Optima" with preliminary selection of sowing discs. The uniformity and seeding rate is best checked on a field road. The distance between the seeds in the row should be $15-20 \mathrm{~cm}$, depending on the width of the rows $(20 \mathrm{~cm}$ with a width of 45 and $15 \mathrm{~cm}$ with a row width of $70 \mathrm{~cm}$ ).

Sunflower anthodes rotate with regards to the sun direction during the day and turn east after flowering. For this reason, it is necessary to sow it in the direction "South - North", thereby the anthodes do not hook on each other and the potential risk of shedding seeds is reduced.

Beet and corn seeders have row rollers and additional rolling is required only on excessively loose soils. In such fields, additional rolling by ringed rollers reduces moisture loss enhances the contact of seeds with soil, and creates better conditions for subsequent harrowing.

Post-sowing rolling on problematic heavy loamy leached chernozems and gray-forest soils, on the contrary, extensively compacts the upper soil layer, increases the formation of cracks in the summer.

\subsection{Crop tending}

Pre-emergence harrowing should be carried out with light or mesh harrows BSO-4 after 4-5 days after sowing in the phase of "white strings" of weeds. The effectiveness of pre-emergence harrowing depends on the fulfillment of the following extremely mandatory conditions. First of all, this technique should be carried 
out precisely after 4-5 days, and not after 2-3 days or after 8-10 days. Under strict observance of the first condition, a harrow actively "combes out" the seedlings of weeds and "white threads" quickly break from the light touch of the harrow. The depth of the teeth should not exceed 3-4 cm. With a shallower depth, the harrow works in an unstable way, weakly destroys weeds, especially in low places (grooves). It is possible to damage a sunflower with a large depth of harrowing. The second prerequisite is the speed of the unit. It should be no more than $5 \mathrm{~km} / \mathrm{h}$ (pedestrian speed). At an increased speed, the harrow jumps out and sticks under its pull in the soil to the depth of the sunflower seeds and damages them severely. The third condition is the unit movement direction. Pre-emergence harrowing must be carried out across the crop. Otherwise, the possibility of the complete destruction of entire rows of sunflower is not ruled out. And finally, the deadline for pre-emergence harrowing is limited by the size of the seedling. Therefore, harrowing should be stopped 3-4 days before the sunflower seedlings appeare. The early annual weeds can be completely destroyed (80-85\%) only if the above conditions are met.

The second harrowing is carried out on seedlings in the phase of 2-3 pairs of real sunflower leaves. The purpose of post-emergence harrowing is the destruction of late (bristle, chicken millet, shiritsa, etc.), as well as mid-early weeds and, most importantly, soil capillaries. It is no coincidence that seedling harrowing is popularly called dry irrigation and it is equivalent in effectiveness to one irrigation with a norm of $400-450 \mathrm{~m}^{3} /$ ha of water. When harrowing on seedlings, it is very important to choose the right phase of sunflower development and time during daylight hours. Thus, in our studies up to $20 \%$ of plants died when being harrowed in the phase of cotyledonous leaves appearance, while in the phase of 2-3 pairs of real leaves, the death of plants did not exceed 7-8 percent. In addition, in the morning and evening hours young sunflower plants are very fragile and easily damaged by harrows due to increased turgor. Therefore, when harrowing in the morning or late in the evening, 1.5-2.0 times more plants die than in the daytime (from 11 to 15 hours).

The quality of preemergents and seed harrowing depends on the technical condition of the harrows. In this regard, before starting work, it is necessary to check their condition, especially the difference between the teeth in height, which should not exceed $\pm 1 \mathrm{~cm}$.

The exclusion of inter-row treatments leads to a strong compaction of the soil, as a result of which its air and water permeability is significantly deteriorated. Therefore, it is required to conduct double inter-row cultivation to a depth of $6-8 \mathrm{~cm}$ on our soils depending on the sunflower field weediness.

Inter-row treatments should be combined with sidedressing of sunflower with nitroammophos (N16P16K16) at the rate of $100 \mathrm{~kg} / \mathrm{ha}$, in physical mass, which is applied by local tape method.

The intensity of cultivation and the destruction of weeds depend on the proper settings of a cultivator. For a cultivator correctly mounted on MTZ-1221, the frame beam in the working position must be parallel to the axis of the rear tractor wheels. In addition, all paws should be in the same plane.

To adjust the working depth of the working bodies, wooden gaskets are installed under the support wheels of the cultivator, the thickness of which should be $2-3 \mathrm{~cm}$ less than the specified processing depth.

In conclusion, it should be emphasized that, when conducting inter-row cultivations, it is impossible to allow cutting of cultivated plants, which is often the case in many farms when a tractor speed is exceeded or when a unit itself is incorrectly adjusted. Thinning of crops leads to a significant decrease in the productivity of the oil field and reduce the work of the entire team to nothing. Therefore, such responsible work should be entrusted only to experienced and conscientious machine operators (Fig. 1).

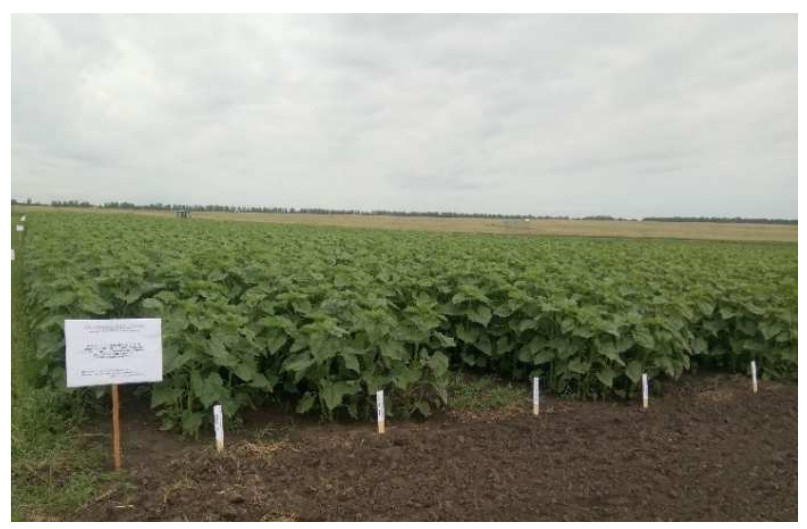

Fig. 1. Crops of sunflower with regards to classical technology of cultivation

In such large holding agricultural formations of Tatarstan as the Krasny Vostok-Agro, Agrosila-Grupp, Ak Bars, Kulonstroy and others the sunflower is cultivated on large areas without inter-row cultivation. In this case, the highest results can be achieved through the acquisition of herbicide designed to test a single hybrid. This weed control system is called Clearfield.

Clearfield is an integrated production system for the sunflower cultivation. It includes the use of special hybrids resistant to specially created imidazoline-based herbicides. The most effective and well-known herbicide is Euro-Lighting, which destroys 70-100 \% of cereal and dicotyledonous weeds without damaging the main crop (Table 1).

In our studies, this herbicide turned out to be especially effective against chicken millet, different types of bristles, wild oats, shepherd's bags, wild radishes, bedstraws, and even yellow and pink thistle. At the same time, it controls creeping wheatgrass and field bindweed weakly (destruction within $70 \%$ ). However, by the time the rows are closed, the competitiveness of these weeds is greatly reduced and they do not cause economic harm.

Such a high efficiency of Euro-Lighting is explained by the fact that it intensively penetrates into the weed plant through leaves, shoots and root systems, that is, it has a contact and soil resistance. To achieve such high results, chemical weeding must be carried out in a phase of 4-6 pairs of real sunflower leaves, which coincides 
with the initial period of growth of both monocotyledonous and dicotyledonous weeds.

Table 1. The spectrum of the herbicide Euro - Lighting impact on sunflower crops, (1.2 1/ha)

\begin{tabular}{|c|c|c|}
\hline English weeds name & Latin weed name & $\begin{array}{l}\text { Destruction } \\
\text { of weeds, } \%\end{array}$ \\
\hline Shepherd's purse & Capsella bursa pastoris & \\
\hline Tansy mustard & Descurania Sophia & \\
\hline Oriental radish & Raphanusraphanistrum & \\
\hline Mustard, species & Sinapis sp. & \\
\hline Jimhill-weed & Thlaspiarvensis & \\
\hline Strumiform burweed & Daturastramonium & \\
\hline Ragweed & Ambrosia artemisiifolia & \\
\hline Lambsquarters & Chenopodium album & \\
\hline Ciliated galinsoga & Galinsogoparviflora & \\
\hline Catchweed & Gallium aparine & \\
\hline Camomile, species & Matricaria sp. & \\
\hline Pickpocket, species & Polygonum sp. & \\
\hline Chickweed satin flower & Stellaria media & \\
\hline Field bindweed & Convolvulus arvensis & \\
\hline China jute & AbuthilonTheophrasti & \\
\hline Amaranth, species & Amaranthus sp. & \\
\hline Barnyard grass & Echinochloa crus-galli & \\
\hline Bristle grass, species & Setaria sp. & \\
\hline Quitch grass & Agropyronrepens & \\
\hline Foxtail & Alopecurusmyosoides & \\
\hline Wheat oat & Avenafatua & \\
\hline Canada thistle & Cirsiumarvense & \\
\hline Yellow thistle & Sonchusarvensis & \\
\hline Tatar molokan & Mulgediumtataricum & \\
\hline
\end{tabular}

Notes:

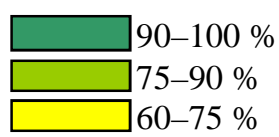

At the same time, the following drawbacks of sunflower cultivation using the Clearfield system should be especially noted:

- to restore normal growth and development after processing the crops with Euro-Lighting herbicide, sunflower needs 12-14 days, which affects the achievement of its harvest ripeness rather negatively, especially in the soil and climatic conditions of the Republic of Tatarstan;

- the use of Euro-Lighting on the crops of other hybrids becomes the cause of the complete sunflower plants destruction;

- its effectiveness sharply decreases when treating the previous culture with similar herbicides (inhibitors);

- most importantly, the chemical load on the environment increases significantly, cost increases as well with concurrent reduction of the sunflower oilseeds production profitability (table. 2 ).

\subsection{Economical effectivity}

The research results were tested at the peasant farm "Minnullin GS", in which sunflower is sown annually on an area of 200 ha (Table 2).
In order to comply with the principle of the only difference between the system of primary and presowing tillage, the fertilizer system for the planned oilseeds yield of $2.0 \mathrm{t} / \mathrm{ha}$, the timing and sowing methods were absolutely identical. The only difference was the weed control system.

Table 2. Economic indicators of sub-sunflower oilseeds production (2015-2019)

\begin{tabular}{|l|c|c|c|}
\hline \multicolumn{1}{|c|}{$\begin{array}{c}\text { Economic } \\
\text { indicators }\end{array}$} & $\begin{array}{c}\text { Units } \\
\text { measuring }\end{array}$ & $\begin{array}{c}\text { Classic } \\
\text { technology }\end{array}$ & $\begin{array}{c}\text { Clearfield } \\
\text { Technology }\end{array}$ \\
\hline $\begin{array}{l}\text { Oilseed } \\
\text { productivity }\end{array}$ & t/ha & 1.86 & 1.80 \\
\hline $\begin{array}{l}\text { In percentage to } \\
\text { the planned } \\
\text { volume }\end{array}$ & $\%$ & 93.0 & 90.0 \\
\hline $\begin{array}{l}\text { Average selling } \\
\text { price }\end{array}$ & $\begin{array}{c}\text { thousand } \\
\text { rubles/t }\end{array}$ & 18.0 & 18.0 \\
\hline $\begin{array}{l}\text { Gross production } \\
\text { value }\end{array}$ & $\begin{array}{c}\text { thousand } \\
\text { rubles/ha }\end{array}$ & 33.5 & 32.4 \\
\hline Total costs & $\begin{array}{c}\text { thousand } \\
\text { rubles/ha }\end{array}$ & 19.8 & 20.3 \\
\hline Net profit & $\begin{array}{c}\text { thousand } \\
\text { rubles/ha }\end{array}$ & 13.7 & 12.1 \\
\hline Profitability & $\%$ & 69.2 & 59.6 \\
\hline Cost price & $\begin{array}{c}\text { thousand } \\
\text { rubles/t }\end{array}$ & 10.6 & 11.3 \\
\hline $\begin{array}{l}\text { Cash proceeds } \\
\text { from product sales }\end{array}$ & $\begin{array}{c}\text { thousand } \\
\text { rubles/t }\end{array}$ & 7.4 & 6.7 \\
\hline
\end{tabular}

Despite this, a comparative assessment of the economic indicators of oilseed production revealed the following significant differences:

- firstly, the high cost of herbicidal treatment of sunflower crops leads to an increase in total costs up to 20.3 thousand rubles/ha, which is higher than 0.5 thousand rubles/ha compared to double inter-row cultivation;

- secondly, excessive soil compaction and absence of fractional application of the calculated norms of mineral fertilizers; the herbicidal technology led to a decrease in yield compared to the classical technology of sunflower cultivation.

For the above reasons, cash proceeds from 1 hectare of arable land in the first embodiment was 0.7 thousand rubles more. The profitability is higher by $9.6 \%$ compared with the sunflower cultivation according to the Clearfield system.

In general, it should be noted that the profitability of the compared technologies applied to the production of sub-sunflower oilseeds ranges from 59.6 to $69.2 \%$, which is $35-40 \%$ higher than the average production of spring wheat in the Republic of Tatarstan.

\section{Conclusion}

The recommended methods of sunflower cultivation do not require replacement of a technical equipment, they easily fit into modern agricultural technology, provide additional production of $0.66-0.86 \mathrm{t} / \mathrm{ha}$ of oilseeds with high economic indicators.

The choice of methods for controlling weed vegetation depends on the power supply ratio and the 
sunflower sown area in a particular farm. If there are inter-row cultivators and limited areas of the research object, preference should be given to agrotechnical measures for weed control, and in holding companies it should be cultivated in large areas and in accordance with the Clearfield system.

\section{References}

1. F.N. Safiollin, R.M. Nizamov, V.M. Panasyuk, S.R. Suleymanov, A.A. Akhmetzyanov, BIO Web of Conf., 17, 00241 (2020)

2. V.M. Lukomets, V.M. Penchukov, N.I. Zaitsev, Bull. of the agro-industrial complex of Stavropol, S2, 85-87 (2015)

3. B.N. Nasiev, A.S. Bushnev, Oil crops, 4(180), 45-49 (2019)
4. V.M. Lukomets, V.T. Piven, N.M. Tishkov, N.I. Bochkarev, S.A. Semerenko, Plant protect. and quarantine, 6, 36-39 (2019)

5. D.T. Khaliullin, A.V. Dmitriev, Modern high technol., 12-2, 272-276 (2015)

6. R.I. Safin, L.Z. Karimova, F.N. Safiollin, Sh.Z. Validov, B.G. Ziganshin, K.Z. Karimov, G.S. Minnullin, E3S Web of Conf., 91, 185-193 (2019)

7. V.F. Moiseichenko et al., Fundamentals of scientific research in agronomy (Kolos, Moscow, 1996), $336 \mathrm{p}$.

8. V.M. Lukomets, N.M. Tishkov, V.F. Baranov, Methodology for conducting field agrotechnical experiments with oilseeds (Krasnodar, 2010), 327 p.

9. B.A. Dospekhov, Methods of field experience (Agropromizdat, Moscow, 1985), 351 p. 